\title{
8
}

\section{META-ANALYSIS OF CLIMATE MITIGATION EVALUATIONS}

\section{Christine Wörlen}

\section{Introduction}

In evaluating climate change mitigation interventions, a large number of questions revolve around the impacts of greenhouse gas mitigation (e.g. Did the intervention actually lead to greenhouse gas emission reductions? Who can claim credit for the reductions?). Although these questions are straightforward in some cases, for example where renewable fuels are directly substituting for fossil fuels, few climate change mitigation interventions in developing countries focus on such a direct switch.

Instead, mitigation interventions focus the majority of their effort on capacity building, policy frameworks, consumer awareness or training of technicians. This complicates the challenge of measuring the impacts, and the challenge of attribution: assessing the relative contribution of each such activity requires a clear understanding of the answers to complex questions, such as why and in what situation which technology is used and what effected a change.

Market and behaviour change can be measurable, but not attributable to the intervention, because factors outside of the intervention also contributed to the change in market conditions. In order to identify an interventions' impact in a given context, it is useful to use a framework to clarify which barriers to the use of the 'better' technology were actually limiting the change for the better in the first place, and if these were addressed effectively by the intervention. Such a framework would constitute an important step towards solving the attribution question in climate change mitigation. Without such a framework, evaluations typically give limited weight to capacity building and policy interventions and most greenhouse gas benefits are attributed to investments.

This study presents the 'Theory of No Change', an 'inverted' theory of change for climate mitigation interventions and a tool for assessing situations why projects 
fail. The core theory is a scheme comprising the barriers that prevent the broader diffusion of a product or keep users and consumers from making more climatefriendly choices. Based on empirical analysis, it was possible to identify a closed set of such barriers, which in their sum are close to representing a full programme theory, the Theory of No Change.

With the help of this framework, we are able to assess whether or not an intervention contributed to a more favourable framework for a sustainable energy technology's market development. This allows a deeper and more useful analysis of an intervention's impacts and potential avenues for improvement than the standard practice of using output-based evaluation.

The Climate Change Evaluators Community of Practice, hosted by the Evaluation Office of the Global Environment Facility (GEF), sponsored this work. The Community of Practice facilitates knowledge exchange, mutual help and inspiration among climate evaluators. It has compiled a library of almost 500 climate change mitigation and adaptation evaluations at the project, programme, policy and portfolio levels. After a number of more formal summaries (e.g. Matambo and Griebenow 2010), this chapter takes a first stab at a fundamental challenge of mitigation evaluations - the quest for a common programme logic of climate mitigation interventions. It can be used as an evaluation framework tool for attributing causality. The framework was first published in a longer version by the Community of Practice (Wörlen 2011a). The author is grateful to the Community of Practice for the support of this work.

\section{Some persistent climate mitigation evaluation questions}

Climate change mitigation initiatives attempt to minimize changes to the global climate by limiting greenhouse gas emissions. Most mitigation efforts have been undertaken in the energy sector, where most interventions strive to replace fossil fuels with non-emitting energy sources or to reduce energy consumption. Many donors, national institutions and private entities undertake projects to that end.

These projects, almost irrespective of whether they take place in developing or developed countries, suffer from a persistent tension - perceived or real - between greenhouse gas-related and developmental objectives. Growth often leads to rising greenhouse gas emissions. Therefore, avoiding greenhouse gas emissions is often put on par with limiting growth. Mitigation projects in the development realm need to reconcile these seemingly contradictory objectives.

Few development interventions directly reduce emissions. Greenhouse gas reducing interventions attempt to facilitate the switch from existing technologies to less- or zero-emitting technologies or fuels. With the exception of the Clean Development Mechanism (CDM), few development-oriented activities help to make that switch directly. Instead, non-CDM climate mitigation initiatives often help build supply chains, policy frameworks, informed demand, technical skills and other types of local capacity, thus enabling the actual users of the greenhouse-gasemitting technologies to use cleaner alternatives. Directly replacing them is not 
typically part of project activities. Rather, most interventions conduct or support activities that cause changes in target groups' behaviour. Projects often educate users about the new technologies, build the new technologies' supply chains or make available financing to buy and operate these technologies. The end users themselves might not even be part of the intervention (e.g. when interventions work with policy makers on regulatory changes or with financiers on the development of financial products).

Thus, most interventions work on a more fundamental level, apply a more indirect programme logic and intend to provide more catalytic impacts towards a climate-friendly way of living. This presents a challenge for results measurement and attribution. Projects' impacts on greenhouse gas emissions are often assessed based on outcome indicators that relate to emission-relevant behaviour (e.g. energy consumption). A number of assumptions are necessary for drawing conclusions regarding the causal link between project activities and greenhouse gas impacts. The basis for these conclusions is necessarily a conceptual model of the relationship between project outputs and outcomes and between outcomes and objectives. Although this is a well-documented challenge for results-based evaluations, the logical chain between a project's interventions and the ultimate objective of climate preservation is particularly long and weakly formulated in many mitigation projects.

This is compounded by the fact that a project's formulation or its underlying conceptual model frequently fails to discuss a large number of preconditions. For example, there is no common understanding on the right set of preconditions for climate-friendly behaviour, appropriate indicators (and on which levels they should be measured), standardized data, data sources and data quality requirements. Often, the mix of preconditions is described as general 'lack of capacity', which hardly clarifies what should be done about it. In addition, mitigation interventions do not start with a blank slate or exist in a static environment. The context in which an intervention takes place and its development over time are highly relevant to the interventions' success. However, contexts are hard to acknowledge, to fully describe and for which to account.

A theory of change that accounts for an intervention's context is the necessary basis for assessing an intervention's results. This theory of change needs to go beyond the linear project logic of any single component. It should also serve as a model for aggregating the outcomes of different activities that might take place at the same time, which can generate synergistic effects, counteract each other or remain independent. They might take place with completely different stakeholder groups, interventions, instruments and on such different time scales that, in evaluations, they are hard to bring into relation to each other.

One challenge in particular compounds this issue: many climate change mitigation interventions will only result in reduced carbon emissions sometime after the project's end and after its final evaluation. The evaluator can only examine intermediary outcomes; conclusions about a project's ultimate impacts with respect to the climate mitigation objectives will need to be drawn based on these interim observations. Necessarily, these evaluations will have preliminary character and the findings 
will remain clouded with significant uncertainty as to the project's ultimate impacts. Improving the underlying theory that links the intermediary outcomes with the ultimate objectives might reduce this uncertainty.

\section{Objective and methodology of the meta-analysis}

A large number of challenges persist in climate mitigation evaluations. One reason for a number of these challenges is that there is no agreed-on programme theory of change regarding how to transform unsustainable energy use into more sustainable use of energy (e.g. by substituting renewable energy for fossil fuels or by shifting towards more energy-efficient, less polluting equipment). Having a clear conceptualization of what is required for behavioural changes to take place would address a significant number of the challenges mentioned - it would help clarify the roles that non-investment-related activities play and how different interventions interact with each other, so that context can be better analysed. The meta-analysis set out to compile theories of change from a large number of evaluations of climate mitigation interventions, to distil a common theory of change.

Such a theory of change can not only form the basis for formulating systematic outcome indicators that reflect the full set of necessary enabling conditions but can also help identify the full scope of evaluations that look for reasons for a project's success or failure (not only in the projects proper, but also in their context). Such a concept would not only be helpful for the evaluation of projects, programmes and policies, but it would also have some predictive power and would be able to support project design and monitoring.

There are a number of necessary preconditions for a market to physically switch towards sustainable energy technologies: the technology needs to be available, local users need to be aware of and create demand for it, they need to understand the new technology and might need some kind of supply chain for maintenance services. Larger investments might require loan financing, as sometimes the amounts of money to be initially invested might be simply unaffordably high despite an investment's long-term cost-effectiveness. Further, in some development contexts an energy-efficient cook stove costing just few dollars might represent a significant outlay to the target demographic. In other cases, policy frameworks might be necessary to level the economic and regulatory playing field between new and traditional technologies. Developing such frameworks requires that policy makers are aware of the benefits of a sustainable energy technology and know-how to create policy frameworks that leverage these benefits. All of these capacities need to be in place.

They refer to a number of different stakeholders which need to be considered when analysing mitigation interventions, in particular those interventions that intend to trigger market development for sustainable energy technologies. After analysing a large number of climate mitigation evaluations, the study on which this chapter is based concluded that for sustainable market development, four main groups of stakeholders play a role: users of the technology, the supply chain (i.e. shops and maintenance technicians), policy makers and local financial institutions. 
Each of these groups typically encounters a number of barriers that keep them from using or supporting the sustainable energy technology. This chapter catalogues the barriers for the relevant stakeholder groups and puts them together in a Theory of No Change, which helps identify why a desired change is not happening. Analysing barriers with the theory can serve to design activities for removing the barriers to change.

The model uses Tokle and Uitto (2009) as the basis for drafting a full set of barriers to be included in the Theory of No Change. For testing, two case studies were undertaken on the basis of evaluations from the Climate-Eval library (Wörlen $2011 b, 2011 c)$. The Thailand case study selected projects that come from the traditional realm of market transformation approaches and tried to analyse whether the Theory of No Change could completely represent the market barriers and their relationship with the ultimate objectives. The second case study, for Poland, worked on the public investment sector (district heating and boiler replacement) and analysed to what degree the market transformation concept and the barrier-oriented Theory of No Change helped to understand processes in the transformation of a larger, bulky investment. These case studies help extend the versatility of the concept and formulate recommendations for evaluative practice and future research needs.

\section{Programme logic for climate change mitigation: the Theory of No Change}

Typical climate mitigation interventions include public awareness campaigns, capacity building for technicians, advisory services for policy makers, provision of information and demonstration projects. Very few climate change mitigation interventions of, for example, the GEF, address direct greenhouse gas emissions on a significant scale. Many more are targeted towards providing an enabling environment for the deployment of energy efficient technologies or renewable energy use. This means that the theory of change for these interventions is necessarily somewhat indirect and hard to express in strong causalities or even quantitative indicators. ${ }^{1}$

\section{The evaluation framework of Tokle and Uitto (2009)}

The challenge is to come up with a strong description of the logic that leads from enabling environments to greenhouse gas reductions. Tokle and Uitto (2009) propose an evaluation framework that illustrates a possible programme logic for such a market transformation intervention (see Figure 8.1). It shows that an enabling environment consists of five different capacities that need to be in existence locally:

- Enabling policies, strategies, standards and certification in place

- Adequate financing available

- Adequate business infrastructure

- Awareness created

- Innovation and technology diffused 


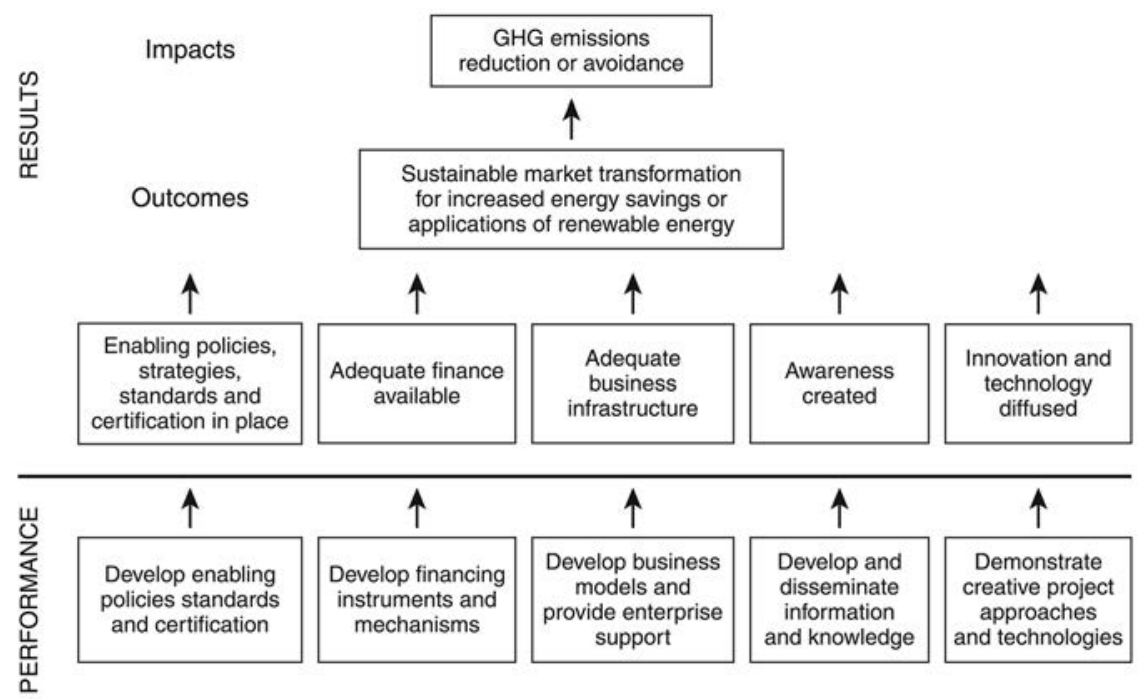

\section{Strategies}

FIGURE 8.1 Evaluation Framework of Tokle and Uitto (2009)

Tokle and Uitto (2009: 143) emphasize that 'normally all these capacities must be in place in order to provide the enabling environment for sustainable development and growth of a market, with supply and demand infrastructure for renewable energy technologies. Market development and removal of barriers to adoption of climate friendly technologies are a continuous process'. When these capacities are in place, the authors describe the intermediate outcome of a climate mitigation intervention as a sustainable market transformation for increased energy savings or applications of renewable energy.

These statements also imply that an intervention addresses only one of these aspects (e.g. it works only with policy makers, financiers or the training of technicians), risks not leading to market change or sustainable energy utilization, as they might neglect other important preconditions. This limits the intervention's potential overall impact. If an intervention chooses to focus on only one small part of the necessary capacities, but still intends to achieve significant greenhouse gas impacts, it needs to ensure that the other capacities either are already in existence or are addressed through other interventions.

Project strategies often work towards one or more of these results (see Figure 8.1). For example, awareness campaigns, technical training, policy formulation assistance or development of energy efficiency standards are all typical activities within climate mitigation projects. Their evaluations, however, will typically remain intervention specific, pay little attention to the context in terms of the other necessary preconditions and thus not be able to analyse all of the previously mentioned attribution and aggregation challenges. Further, the evaluations will not be able 
to reflect the context of the local market situation in terms of the other necessary preconditions, as there is no baseline and no absolute standard of 'how it should be'.

In their framework, Tokle and Uitto (2009) implicitly acknowledge that a multitude of stakeholders are involved in market transformation. For example, consumers, businesses, financial intermediaries and policy makers all constitute relevant target groups. Policy makers are responsible for providing the necessary policy framework; banks and financiers need to be available for financing the energy transformation; service providers and technology companies need to install, sell, operate and/or maintain the new energy equipment; and all these groups and individuals need to be well informed and aware of the new technologies and opportunities. Figure 8.2 maps which strategy can apply to which stakeholder group.

\section{Evaluation framework}

Figure 8.2 illustrates that the stakeholders find themselves in different positions in Tokle and Uitto's (2009) framework. In terms of sustainable energy use, important agents include the users of energy or energy-using equipment; the supply chain of sustainable energy technologies, fuels and maintenance services; the financiers for both supply chain enterprises and users of energy technologies; and policy makers (in the widest sense of the word) who need to provide conducive framework conditions for deploying sustainable energy technologies and services. For each group of agents, it is important to identify the reasons why he or she does not yet behave in

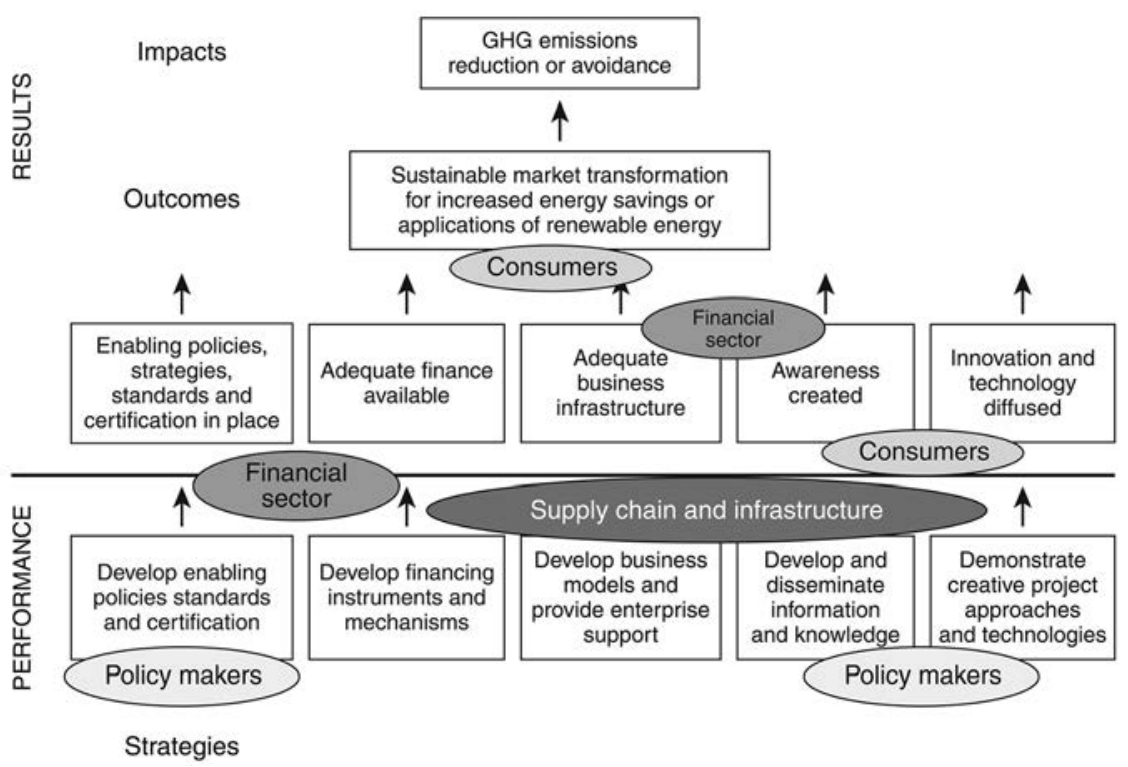

FIGURE 8.2 Evaluation Framework of Tokle and Uitto (2009) with Stakeholder Groups 
an climate-friendly manner (i.e. does not yet use the sustainable energy technology in question, foster it with supportive policy schemes, finance investments into this technology or selling or servicing that technology). These reasons can be understood as the barriers to climate-friendly behaviour and sustainable energy systems.

Mapping stakeholders onto the Tokle and Uitto (2009) framework makes it possible to rearrange the strategies from a focus on enabling capacities towards a focus on removing barriers: if all stakeholders play their respective role with respect to the strategies, the desired outcome of greenhouse gas savings ensues. By turning this around, we can identify strategies along the lines of the stakeholders and find the reasons why a situation might not change.

The absence of enabling capacities poses a barrier to market development that can be measured in a more generalizable and standardizable way for a larger number and scale of interventions. If the barriers are gone - the enabling capacities are present - the situation is going to change and gravitate to the desired behaviour or market situation. This 'Theory of No Change' thus formulates a framework describing the complete set of conditions that might be barriers to more efficient behaviour for all relevant stakeholders.

\section{An abstract description of the potential barrier types}

Analysing a large number of evaluations for two sectoral developments (energy efficiency in Thailand and district heating in Poland, both over almost two decades; Wörlen 2011b, 2011c) has enabled the identification of seven generic barriers that can be observed for almost all stakeholder groups:

1. Ignorance: Stakeholders might not know that a technological alternative exists. This is a particularly obvious barrier for consumers and users - if they do not know that an alternative to their current unsustainable behaviour exists, they cannot use it. However, all the other market stakeholders also need to be aware of the more sustainable alternative in order to play their respective role in the market. In terms of Figure 8.1, awareness needs to be created throughout the market that is to be changed.

2. Lack of expertise: Even if people know about the technologies, actually using, marketing or servicing them might require specific technical knowledge or skills. In this analysis, expertise is defined for each stakeholder group as the specific skills that are required in the transformed market. Training of technicians is particularly important for the supply chain, and many technology programmes in developing countries and technology suppliers provide it. In addition, policy makers need some expertise in order to provide a supportive policy framework, and financiers need to have the skills to evaluate a new technology in its context.

3. Lack of access to technology: Even if sufficient people are trained in using the technology, the technology might not be available in the local market. That 
might be an expression of insufficient capacity along the supply chain, which might or might not be caused by a lack of financing or one of the other barriers to building up a sustainable supply chain. However, in many cases it is related to policies in unrelated domains (e.g. terms of trade, taxes, tariffs, administrative procedures and other policy areas). This barrier is important for users and for the supply chain.

4. Lack of motivation: Even if the technology is accessible, people are aware of it and know how to use it, and even if it might be cost-effective compared to the conventional alternative, people might still not be interested in using, supplying, financing or politically supporting it. Reasons for this might lie in the image connected with the old technology, in the realm of prejudices, or perceived risks or bad experiences with the new technology. A lack of motivation might also be associated with an overall resistance to change. Lack of motivation can affect all stakeholder groups (with the possible exception of financiers).

5. Lack of cost effectiveness: One barrier is that on a total cost of ownership basis, the technology might be more expensive than the established technology. This can be due to a number of factors, such as fossil fuel subsidies or the newness of the technology. Barring substantial technological advances, using hydrogen fuel cells for self-consumption instead of subsidized grid electricity might be more expensive in both the long and short run, and will therefore not be a popular choice.

6. Lack of affordability: Even if a technology is cost effective under totalcost-of-ownership considerations, sustainable energy technologies are often associated with high upfront costs and low operating costs. For example, wind turbines entail a large investment but have no fuel costs so that in good wind locations the production of a unit of wind power might be cheaper than coal power. However, if no investment financing for these technologies is available (e.g. in the form of investment capital, equity or loans), the technology will not be deployed. This lack of working capital is a barrier for both consumers and supply chain actors. In addition, financiers might have issues in providing loans due to their own liquidity issues. Policy makers may want to finance incentives but not have the fiscal means to do so.

7. Lack of demand/business model: For some products, it is necessary that the market reaches a specific size in order for the supply chain to build up or for financiers to become available. If this is not the case, innovative business models could reduce this barrier. For example, energy service companies can use innovative loans or rental schemes (leasing or exclusive-use contracts) so that stakeholders in a niche market can pioneer the technology.

8. Projects, policies and programmes in the climate mitigation area typically try to remove one or more of these barriers. As discussed, the same barrier might apply to different stakeholder groups. For example, policy makers, financiers and users all might not trust new technologies in terms of their technical performance. For these generic barriers, the same barrier removal strategy - and 
sometimes even the same activity - can be used, tailored to the respective stakeholder group. The more comprehensive the programme, the more barriers are addressed. In the best of worlds, all barriers that exist in a specific context are identified at the project design phase and comprehensive barrier removal strategies are designed accordingly.

\section{The stakeholder-barrier matrix}

If every stakeholder group encountered every barrier, a matrix with 28 barriers would result. However, not all barriers are relevant for all stakeholders. The following section discusses what barriers can be eliminated by theoretical considerations in order to reduce the number of barriers that are necessary to draw the full picture.

For example, for financiers and policy makers, it makes no difference whether they have access to the technology as they will not use it themselves - they will only provide the financing or regulatory frameworks for it. The concept of a 'business model' should also not be applied to policy makers. Excluding these irrelevant barriers allows us to draw a reduced stakeholder-barrier matrix (see Table 8.1).

For users, the different business cases result in different cost-effectiveness and are therefore subsumed under cost-effectiveness. For now, another barrier disregarded in the next stages of discussion is the supply chain and financiers' potential lack of interest and motivation - here it shall be assumed that the supply chain consists mostly of organizations that strive to increase their business and will not need extra motivation if they see a new business opportunity or can expand their product offerings. It is also assumed that a lack of liquidity with financiers constitutes the same barrier to financiers' engagement as a lack of cost effectiveness. Excluding these irrelevant barriers allows the drawing of a reduced stakeholder-barrier matrix (see Table 8.1).

A case study based on ten evaluations of energy efficient market transformations in Thailand was used to test whether this set-up of stakeholder groups and barriers is able to reflect the situation in the market. The model was tested for the number of stakeholder groups to be included: consumers/users of equipment, the supply chain that delivers hardware and maintenance services, policy makers who create the enabling policy framework and the financiers that provide for the necessary financial liquidity.

One test was whether the implementing agency should be part of the model. This was rejected as barriers are only relevant for those stakeholders that play a role in the functioning market after project implementation. If implementing agencies are not active in one of the markets in one of the four roles mentioned earlier, their barrier situation is irrelevant for the actual functioning of the market. Once the market is sustainably operating, there is no need for further activities of the implementing agency or a special role in the barrier circle. Their activity is expressed 
TABLE 8.1 Example for Barrier Removal Strategies

\begin{tabular}{|c|c|c|}
\hline Stakeholder group & Barrier & $\begin{array}{l}\text { Barrier removal strategy, } \\
\text { project activity }\end{array}$ \\
\hline \multirow[t]{6}{*}{ Consumer/user } & Ignorance & $\begin{array}{l}\text { Awareness campaign, } \\
\text { pilot project }\end{array}$ \\
\hline & Lack of expertise & Product design \\
\hline & Lack of access & Build-up of supply chain \\
\hline & Lack of affordability & Subsidy \\
\hline & Lack of interest/motivation & Awareness campaign \\
\hline & Lack of cost-effectiveness & Product design \\
\hline \multirow[t]{6}{*}{ Supply chain } & Ignorance & $\begin{array}{l}\text { Awareness campaign, } \\
\text { pilot project }\end{array}$ \\
\hline & Lack of expertise & Training \\
\hline & Lack of access & Trade facilitation \\
\hline & Lack of affordability & $\begin{array}{l}\text { Facilitating finance } \\
\text { through special or } \\
\text { mainstream financial } \\
\text { intermediaries }\end{array}$ \\
\hline & Lack of cost effectiveness & Support policies \\
\hline & Lack of business model & $\begin{array}{l}\text { Support for business } \\
\text { model development, } \\
\text { demonstration and } \\
\text { marketing }\end{array}$ \\
\hline \multirow[t]{4}{*}{ Policy maker } & Lack of motivation & $\begin{array}{l}\text { Awareness campaign, } \\
\text { pilot project }\end{array}$ \\
\hline & $\begin{array}{l}\text { Misinformation w.r.t. abate- } \\
\text { ment options }\end{array}$ & Training \\
\hline & Lack of expertise & Advisory support \\
\hline & Lack of fiscal affordability & Financial transfers \\
\hline \multirow[t]{4}{*}{ Financier } & Ignorance & Awareness campaign \\
\hline & Lack of expertise & Training \\
\hline & Lack of cost-effectiveness & $\begin{array}{l}\text { Training, financial sup- } \\
\text { port facilities (e.g. guar- } \\
\text { antees, concessions) }\end{array}$ \\
\hline & Lack of business model & $\begin{array}{l}\text { Support for business } \\
\text { model development, } \\
\text { demonstration and } \\
\text { marketing }\end{array}$ \\
\hline
\end{tabular}

in the project mapping. Thus, it is not helpful to include them in the stakeholder groups of the Theory of No Change.

A number of barriers might apply only to specific subgroups of the stakeholder groups or specific product markets. For example, in the market transformation from 
incandescent light bulbs to compact fluorescent light bulbs, users do not need any additional expertise in using the light bulbs (their functionality is exactly the same for both products). The case study in Poland used examples from a number of large investment programmes in energy efficient heating and district heating. In district heating, consumers often do not have a choice. Heat is provided by a utility, and supporting services might be provided by a private sector supply chain. So, depending on the project set-up or the market complexity, it might be necessary to adjust the TONC, e.g. by splitting the stakeholder group of supply chain actors into several subgroups. And again, not each stakeholder group faces all barriers. In the case studies on Poland for example, three more barriers were found to be irrelevant for these particular groups.

Across all market situations studied in Thailand and Poland, two barriers were consistently found to not significantly impede market development. These were 'access to technology' for the supply chain and 'ignorance' for policy makers. It reflects well on the projects that these two barriers were not relevant in the country cases studied. 'Access to technology' was possible for the supply chain in these cases, which meant that international technology markets were effectively supplying the countries with the necessary technologies. For the most part, the implementing agencies sufficiently included policy makers in the interventions in order to make them aware of the technologies and energy efficient options that were available. Where it can be assumed that this will be the case for most countries and most energy technologies (except nuclear power) it might be possible to shorten the concept by these two barriers.

Barriers might not be independent. For example, whenever 'lack of affordability' for the supply chain was an issue at the project outset (only in the cases of coal to gas and geothermal in Poland), the 'lack of business model/demand' barrier was a dispositive barrier to market development. When the 'lack of demand' barrier was removed, the suppliers were also able to afford the investment into these new lines of business. In those cases in which lack of affordability for the supply chain is observed the barrier can be reflected on the financiers' side. However, this might not apply in other areas. For example, in the area of off-grid electrification, higher electrification rates can only be reached with higher capital infusions. Therefore, one of the two barriers could be taken out, and in later applications of the Theory of No Change, we have mostly left out the barrier of 'lack of business model/demand' as it was shown to be a compound of other barriers, and its inclusion did not lead to additional analytical power.

Other barriers appear to have had a negligible impact on market development in the case studies. In particular, the lack of motivation for policy makers has not effectively hampered market development in these cases. However, government support is part of the decision-making system of most official development assistance bodies, and therefore, it is not surprising that in all the projects analysed here, the government was motivated to support market development. If these were private sector- or civil society-driven market changes, governments' motivation might have been a 
barrier. Therefore, it is not recommended to generally leave out this barrier but be judgemental about that.

\section{A mapping tool for barriers and interventions}

An underlying assumption of the barrier discussion for market transformation is that all relevant barriers need to be removed in order for market transformation to take place. This can be addressed with a checklist. A visualization tool has been developed that illustrates barrier intensity with traffic light colours (see Figure 8.3). It can be combined with a visualization of the project intervention (see Figure 8.4) so that the line-up of the intervention with the barriers can be assessed at one glance (see Figure 8.5).

\section{The barrier circle}

Figure 8.3 represents the market as a circle with four segments representing the four stakeholder groups (users/consumers, supply chain, local financiers and policy makers). The barriers, according to Table 8.1, are represented by small elements labelled with the name of the barrier. Each element can be coloured according to the strength of the barrier in a specific market situation. This colour code follows the globally accepted colour scheme of a traffic light, but with two intermediate steps (yellow and orange) instead of only one. Green is a situation that is favourable to market change. Yellow is a situation that is not necessarily favourable, but there is no significant barrier. Orange and red are barriers that impede market change (orange is the colour for a situation that significantly slows down market change; red is the colour for a barrier that can bring market development to a halt). As long as there is a red barrier for any single factor, the market will not change in any meaningful way.

The example in Figure 8.3 is taken from the case studies and relates to a market where the financiers' activities, attitudes and awareness levels do not fully stop, but do slow down the change in the market, particularly due to a 'lack of business model' (i.e. they did not encounter enough demand to develop a financial product). This is symbolized by the yellow and orange wedges in the financiers' part of the circle in the lower right segment. Policy makers - the lower-left segment of the circle - know of the opportunity (as indicated by the green of the 'ignorance' barrier), are motivated to put in place the appropriate policies and frameworks (as indicated by green of the 'lack of interest/motivation' ring segment) and have the fiscal means to do so - indicated by the green colour of the 'lack of affordability' ring segment. However, policy makers do not know which would be the right policies or how to implement them. Thus, 'lack of expertise' is coloured orange: it constitutes a significant barrier to market change. None of these barriers would necessarily be an absolute bar to market change without an intervention. But as shown in Figure 8.3 , the consumers' ignorance and the lack of cost effectiveness of an engagement 


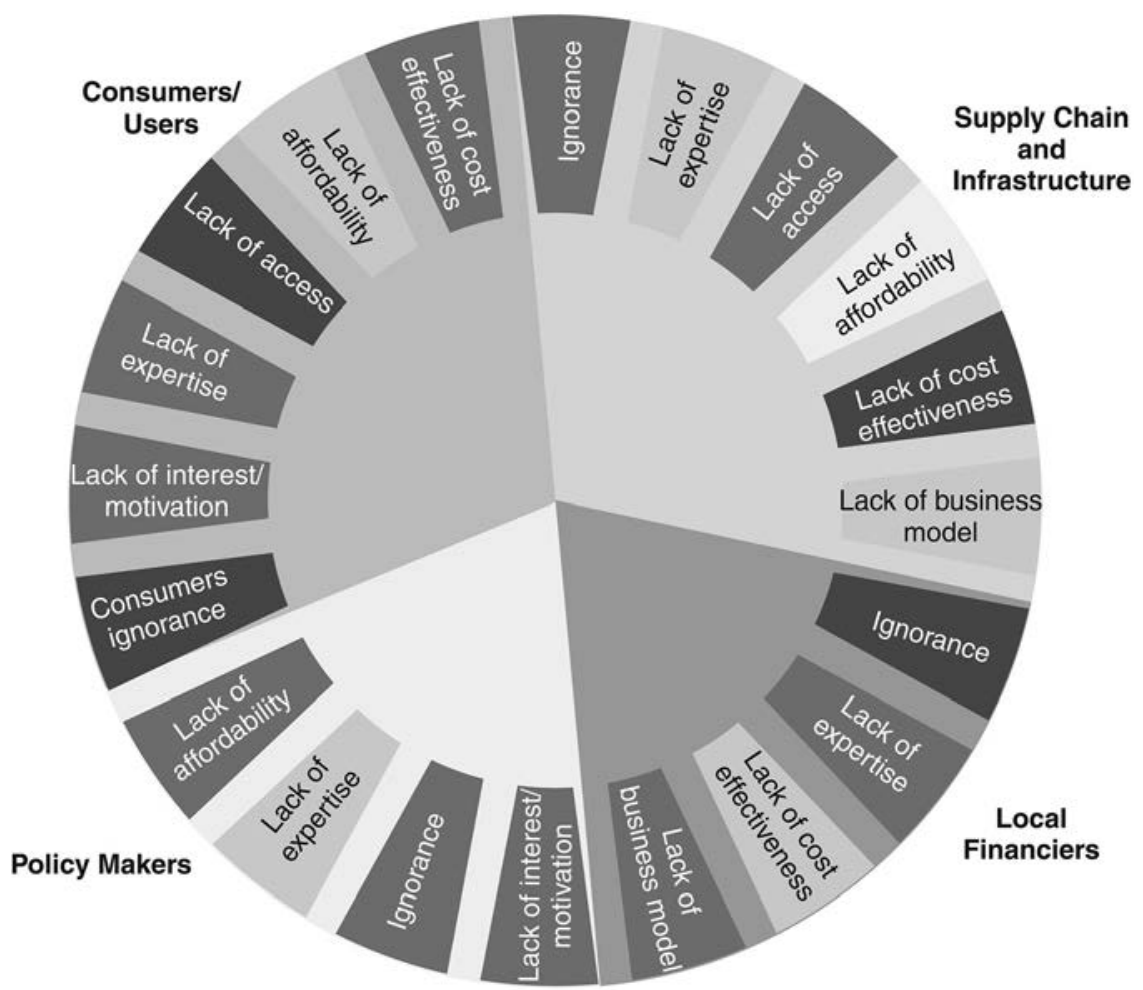

FIGURE 8.3 Example for Mapping the Barriers in the Barrier Circle Diagram

of the supply chain in the market are red, indicating that they are absolute barriers preventing a functioning market for energy-efficient products from developing.

The barrier circle can be used for project planning up front and can help identify the relevant barriers and design the appropriate barrier removal strategies. Comparing the barrier circle is drawn for the situation before and after the project illustrates the barrier removal impact of a project.

\section{The intervention circle}

Figure 8.4 presents an example from the case studies of the second part of the visualization tool, the intervention circle. The spikes on the spider web point in the same as the direction as the barrier they are designed to address. The axis signifies the intensity of the intervention: the farther out the points lie on the spider web, the more intense is the project's focus on these activities. The intensity of the barrier removal activities is ranked on a scale from zero to five. So far, no methodology can serve to calibrate the intensity of the barrier removal activity as compared to the intensity of the barrier. Therefore, the relative rank of the activity relates to its 


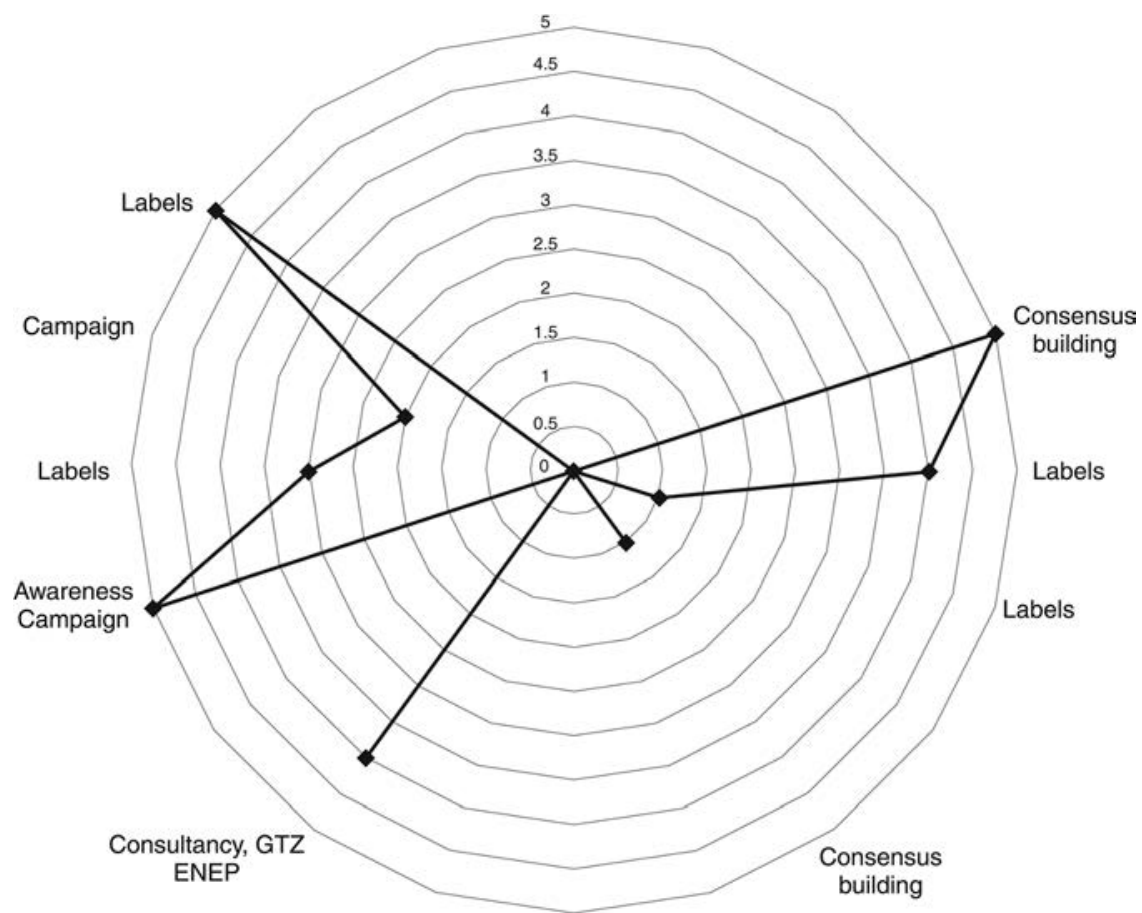

FIGURE 8.4 The Intervention Circle

importance within the intervention. The most important element of an intervention is given the highest ranking of five. Other, less important parts of the intervention received lower rankings, in relation to their relative importance within the intervention.

In the example presented in Figure 8.4, the project consisted of several activities: a consultancy helped policy makers develop expertise on smart policies, in this case a labelling policy for energy efficient appliances. The project built a consensus on the labelling system among manufacturers of these systems so that a joint move towards more market transparency through the labels created a business case for the suppliers to produce and distribute more efficient appliances. An awareness campaign helped consumers understand the energy efficient product and the energy efficiency labels. A part of the awareness campaign worked on the motivational barrier, by making it 'the cool thing' to buy the appliance with the energy efficiency label. Side effects of these activities were that financiers also started to understand the market for energy efficient appliances (through the labels) and found it a costeffective market opportunity (through the consensus building exercise whose primary target group were the manufacturers).

Thus, with the help of the intervention circle, each project is illustrated as a characteristic fingerprint of barrier removal activities. If interventions or intervention 
components cannot be mapped on this circle, their contribution to market development might be limited or at least unconventional. On the other hand, the intervention circle does not distinguish between projects carried out by different actors, stakeholder groups or agencies. It can also capture the activities of several projects and interventions going on in parallel. All of them can be mapped onto a single spider web diagram which highlights potential synergies and complementarities (as well as potential conflicts) at a glance.

\section{Putting the two together}

Figure 8.5 illustrates how the two tools shown in Figures 8.3 and 8.4 can be combined to illustrate an intervention's match with the existing barriers in a market. A simple overlay of the two diagrams illustrates the degree to which the activities align with the barriers. In the example presented here, the consensus achieved with the supply chain and the energy efficiency labels directly addressed the lack of awareness for this not-yet-cost-effective product and created a new business model, consisting of selling energy efficient appliances in addition to the original appliances. This improved consumers' access to the energy efficient appliance. The awareness campaign informed consumers and users about the energy efficient option, and the labels motivated consumers to buy the more energy efficient appliance. Another

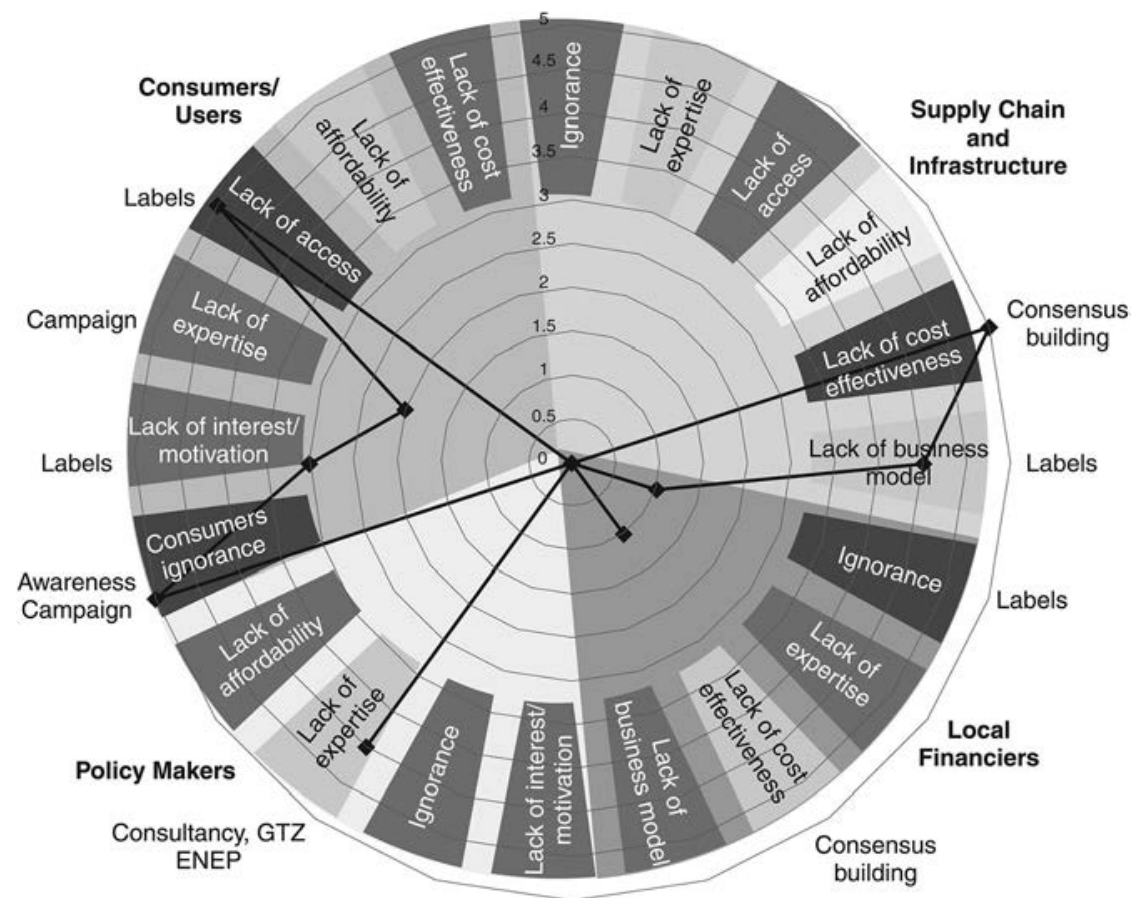

FIGURE 8.5 Barrier Circle and Intervention Circle Diagram 
project component assisted policy makers in becoming smarter about energy efficiency labelling policies, their development and their enforcement. However, the overlay of the diagrams also shows that a number of yellow and orange barriers were not addressed by project activities. It seems that these barriers were not removed successfully through the intervention. If they are not in place after the intervention anymore, this would have to be attributed to other factors that were not part of the project.

This example illustrates how, together, the barrier circle and the intervention circle can give an indication of the likelihood for success of an intervention at the design stage of a project. When used in evaluation, the direction of the lines in the Intervention Circle will be aligned with those barriers that they actually addressed (even if they might have been designed to address other barriers or without an explicit barrier removal consideration). The tool is able to illustrate the sector in a holistic manner and reflect that barriers are sometimes not independent. It also reflects the barriers in their relative importance: If an intervention is designed on the basis of a sound barrier analysis, it will typically strive to remove the red barriers. If the red barriers are removed, the market might grow to some degree but market transformation most likely will be slowed down if orange barriers remain. As markets develop, new barriers that used to be orange will then come up and become 'red lights'. New barriers can also be created by external factors such as changes in government, financial crises, failure of technical infrastructures or new technological developments. The traffic light system will reliably indicate these barriers in updated analyses.

\section{Summary and outlook}

Effective climate change mitigation requires a long-term fundamental transformation of almost all energy-consuming processes in society. In order to reach a climate-compatible energy system - and this is true for many other areas of greenhouse gas emissions as well - we need a close-to-complete transformation of the way we provide and use energy. Project designers are aware that their efforts can only be small steps on this long path. Thus, most projects strive for some catalytic or transformative impacts that would trigger changes beyond the actual scope of the interventions. Most of the project documents formulate this explicitly as part of their motivation or even as their objective. Their mission is to contribute to an altered way of energy use by creating an enabling environment, rather than replacing every light bulb.

The larger goal of reduced emissions is many causal steps removed from whatever a project can achieve. This creates a significant attribution challenge. In order to better define the logical linkages between the steps and the goal, this chapter has developed a programme theory for climate mitigation intervention that allows assessing contributions to the larger goal. It looks not at positive contributions but at effects of removing barriers - where they exist nothing happens. When they are removed, change can take place. 
This concept gave the programme theory its name: Theory of No Change. The concept has been developed on the basis of three sources: The online library of mitigation evaluations of the Climate Change Evaluation Community of Practice, the Evaluation Framework of Tokle and Uitto (2009) and the concept of market transformation for energy efficient consumer goods.

It has then been tested on two case studies (energy-efficient products in Thailand and district heating in Poland), for which a large number of evaluations were available. In these, four types of stakeholders played a role: consumers who constitute demand, suppliers who satisfy it, financiers who provide the financial liquidity in the market and policy makers who set the framework conditions. These groups of stakeholders typically encounter a number of barriers that keep them from using or supporting the sustainable energy technology. Seven generic barriers have been identified (not all of which apply to all stakeholders).

This resulted in a full programme theory for market development, and as such the Theory of No Change is able to assess whether or not an intervention has been contributing to a more favourable framework for market development for a sustainable energy technology. Rather than a positive log-frame-type theory of change, the Theory of No Change reflects the relevant context for change and provides a theory for what might have been limiting the success of the intervention. This is also important in order to identify to what degree the contribution was really decisive for change. Was the project really effecting change, or was an impact only perceived because it took place together with other changes in the market - changes that might have been even more decisive in spurring a change in market conditions? By including context into the analysis, the Theory of No Change is a step towards solving the attribution question in climate change mitigation, which will typically limit the importance given to capacity building and policy interventions and attribute most of greenhouse-gas benefits to investments.

Further research is needed in testing the Theory of No Change in other mitigation fields beyond retail products and heating systems so that a Generalized Programme Theory for Climate Change Mitigation can arise step by step. This will help identify where a more flexible approach is needed and how it can be formulated. If a general specification can be found, it can be used not only in project evaluation but also in monitoring and project design. As the Theory of No Change is able to reflect the context, it can also be used for policy evaluations as well as project planning.

As the barrier circle includes almost 20 barriers, this analysis requires some effort. It can potentially be reduced by identifying SMART ${ }^{2}$ elegant outcome indicators or comprehensive analysis methods (e.g. surveys). Some further analysis is required in order to reduce the necessary empirical effort, for example, through more standardized outcome indicators for barrier removal activities.

Discussions with evaluators from other areas have demonstrated that the Theory of No Change can be applied to other areas of evaluation, policy making and change management. Whenever we are concerned with effecting change in people's 
behaviours, in theory, we can ask ourselves what it is that keeps people from behaving in a beneficial way and then remove the barriers to 'better' behaviour.

\section{Notes}

1 The notable exception to this are the project-based Kyoto mechanisms, such as the Clean Development Mechanism, in which each project needs to prove direct greenhouse gas emission reductions. They also rely to a significant degree on other interventions for project identification and development.

2 That is, Specific, Meaningful, Attainable, Relevant, Time-Bound.

\section{References}

Matambo, S. and G. Griebenow, 'Report on the inventory of climate change evaluations, 2010', Unpublished manuscript.

Tokle, S. and J. Uitto, 'Overview of climate change mitigation evaluation: What do we know?' In: R. van den Berg and O. Feinstein, eds., Evaluating Climate Change and Development, World Bank Series on Development,Volume 8, New Brunswick, NJ, and London, Transaction Publishers, 2009.

Wörlen, C., 'Meta-evaluation of climate mitigation evaluations', Study for the Climate Change Evaluation Community of Practice, 2011a, available at http://www.climate-eval.org/www. climate-eval.org/?q=system/files/studies/Meta-Evaluation\%20of\%20climate\%20mitigation\%20evaluations.pdf, last accessed September 122013.

Wörlen, C., 'Meta-evaluation of climate mitigation evaluations: Case study: Transforming markets for energy efficient products in Thailand', Study for the Climate Change Evaluation Community of Practice, 2011b, available at http://www.climate-eval.org/www.climate-eval. org/?q=system/files/studies/Meta-Evaluation\%20-\%20Thailand\%20Case\%20Study.pdf, last accessed September 122013.

Wörlen, C., 'Meta-evaluation of climate mitigation evaluations: Case study: Poland's heat sector', Study for the Climate Change Evaluation Community of Practice, 2011c, available at http://www.climate-eval.org/www.climate-eval.org/?q=system/files/studies/MetaEvaluation\%20-\%20Poland\%20Case\%20Study.pdf, last accessed September 122013. 